East African Medical Journal Vol. 77 No. 11 November 2000

INTRAOPERATIVE COLONIC IRRIGATION IN THE MANAGEMENT OF LEFT SIDED LARGE BOWEL EMERGENCIES IN JOS UNIVERSITY TEACHING HOSPITAL, NIGERIA

A. Sule, FMCS, FWACS, P.O. Obepka, FMCS, FWACS, FRCS, D. Iya, FRCS, FWACS, B., Ogbonna, FMCS, FWACS and J. Momoh, FWACS, FRCS, Department of Surgery, Jos University Teaching Hospital, P.M.B. 2076, Jos, Plateau State, Nigeria.

Request for reprints to: Dr. A. Sule, Department of Surgery, Jos University Teaching Hospital, P.M.B. 2076, Jos, Plateau State, Nigeria.

\title{
INTRAOPERATIVE COLONIC IRRIGATION IN THE MANAGEMENT OF LEFT SIDED LARGE BOWEL EMERGENCIES IN JOS UNIVERSITY TEACHING HOSPITAL, NIGERIA
}

\author{
A. SULE, P.O. OBEPKA, D. IYA, B., OGBONNA and J. MOMOH
}

\begin{abstract}
Objectives: To evaluate the safety and benefits of antegrade intraoperative colonic irrigation (lavage) and primary anastomosis, after colonic resection, in the treatment of left sided large bowel emergencies.

Design: A prospective descriptive study.

Setting: Jos University Teaching Hospital, Jos, Nigeria.

Participants: Thirty seven patients with an average age of $44.86 \pm 16.15$ years.

Intervention: Sigmoid colectomy was performed in twenty two sigmoid volvulus, five sigmoid cancer, two faecal fistulae and one sigmoid injury. Left hemicolectomy was offered in four descending colon cancer, one descending colon injury, while anterior resection was carried out in two rectal cancers. Primary anastomosis was performed after intraoperative colonic lavage.

Results: The operative mortality was $2.7 \%$, anastomotic leakage rate $2.7 \%$ and superficial wound infection occurred in $10.81 \%$. The average duration of hospital stay was $22.76 \pm 11.26$ days. Intraoperative colonic lavage added $35.79 \pm 7.25$ minutes to the operating time.

Conclusion: The results of this study suggest that intraoperative colonic lavage is an effective method enabling the surgeon to perform a primary anastomosis with reasonable safety after emergency resection of selected distal colonic lesions.
\end{abstract}

\section{INTRODUCTION}

Faecal loading and heavy bacterial overgrowth have been found to constitute a major cause of anastomotic dehiscence and wound infection, thus increasing morbidity and mortality following large bowel surgery. The above two factors have been speculated to work partly mechanically and partly through infecting the suture line and so disturbing collagenase activity(1-3). Clinical and experimental evidence support the view that a clean bowel is an important factor in surgery of the left colon and rectum, which are those parts of the bowel with solid faeces and a high bacterial count $(1,4,5)$.

Methods employed to achieve a clean colon include use of oral aperients, rectal enemas, colonic wash-outs, elemental diets and whole gut irrigation. However, these methods are not applicable during emergency surgery of the left colon. Under these circumstances, the orthodox approach has been to perform a staged procedure. For long, this has also been the practice in our centre. However, since this method involves multiple surgical procedures, the patient must suffer extreme surgical and psychological stress, protracted hospitalisation and added expenses.
Staged operations are not commonly acceptable among our patients in Nigeria. This is because of poverty and low level of literacy. Furthermore, care of stoma is difficult and on account of ignorance and social taboo, our patients have a morbid aversion to colostomies(6,7). The performance of a one-stage operation, is therefore even more relevant in our society. We, therefore, report our experience of primary suture of the left sided colon and rectum after intraoperative colonic lavage in the management of left sided large bowel emergencies.

\section{MATERIALS AND METHODS}

During the period May 1993 to December 1996, thirty seven patients managed by the authors underwent emergency left sided colonic and rectal resection with primary anastomosis. Twenty two of the patients had sigmoid volvulus, nine had left sided colonic cancer, and two had rectal cancer. Two patients had faecal fistula of sigmoid origin and the remaining two had penetrating abdominal injury involving descending and sigmoid colon. The twenty two patients with sigmoid volvulus presented in hospital within 24 to 48 hours of sudden onset of abdominal pain in the left lower quadrant, distension and constipation. Only five cases required further evaluation by plain x-rays to establish 
diagnosis. There were nine patients with resectable obstructed left sided colonic cancer, four in the descending colon and five in the sigmoid (two being direct spread of carcinoma to sigmoid from the small bowel and caecum). Diagnosis of colon cancer was made at laparotomy and eventually confirmed at histology. Two patients aged 38 and 20 years with proximal rectal cancers presented rather insidiously with lower abdominal pain, increasing difficulty in passing stool and abdominal distension. Both patients had vomited on few occasions and had features of dehydration and intestinal obstruction and rectal bleeding. Two patients aged 23 and 28 years had iatrogenic faecal fistula with localised peritonitis.

All the patients had urinalysis, haemoglobin level, electrolyte and urea done. Chest $\mathrm{x}$-ray was done in all patients who were over forty years of age and those with suspected mitotic lesions of the colon. Serum creatinine and protein were done in less than a quarter of the patients and all were within normal limits.

All the patients were resuscitated with intravenous fluids and homologous blood transfusion where necessary before subjecting them to any surgical procedure. Intravenous antibiotics (ampicillin 500mg, metronidazole 500mg and gentamicin 2mg/ $\mathrm{kg}$ body weight - maximum of $160 \mathrm{mg}$ for an $80 \mathrm{~kg}$ patient) were administered at induction. Two further doses were given at 8 hours interval post-operatively. A seven day course of these systemic antibiotics was given to the two patients with faecal fistula. The patients were considered fit when the haemoglobin was at least $10 \mathrm{~g} / \mathrm{dl}$ and urine output $30 \mathrm{ml}$ or more per hour.

A vertical low midline laparotomy incision was employed to enter the peritoneal cavity. On-table antegrade colonic irrigation as described by Dudleyet al ( 8 ) was used to clean the colon. All the patients with sigmoid volvulus had detorsion of the twisted sigmoid, intraoperative colonic irrigation, sigmoid colectomy and primary anastomosis. The four patients with descending colon cancer had a left hemicolectomy while the remaining five with sigmoid cancer had sigmoid colectomy. Two patients with rectal cancer had anterior resection. Sigmoid colectomy and primary anastomosis was carried out in the two patients with faecal fistula. The last two patients had left colon and sigmoid penetrating injury, colectomy and primary anastomosis was carried out following intra-operative colonic irrigation. The operative field and wound in all patients with significant contamination and established peritonitis were lavaged with tetracycline solution $(1 \mathrm{mg} / \mathrm{ml})$. Two layer anastomosis was carried out with an inner continuous layer of $3 / 0$ chromic and an outer interrupted seromuscular layer of $3 / 0$ silk. The vertical low midline laparotomy incisions were closed by mass closure using monofilament nylon.

Intra-operative and post-operative homologous blood transfusion was occasionally employed in the event of significant blood loss. The clinical course and post-operative complications were carefully documented. Morbidity was defined as either major or minor. Minor morbidity included wound infection that needed only minor treatment such as dressing only. Major morbidity included more significant wound infection that needed drainage and packing, anastomotic leaks (defined as a presence of frank faecal fistula or anastomotic breakdown seen either at sigmoidoscopy, laparotomy or postmortem, in association with peritonitis) and abscess formation with prolonged hospital stay. Wounds were assessed daily. Wound sepsis was defined as a presence of pus either discharging spontaneously or requiring drainage. Samples of wound discharge were obtained for bacteriological culture. Hospital stay was defined as the total time spent in the hospital for the present complaint and if necessary for a subsequent procedure resulting from complication of primary pathology while mortality was considered as death occurring in hospital.

\section{RESULTS}

The outcome of the application of the method to emergency resection of the distal left colon and rectum without a covering colostomy in the 37 patients is shown in Tables 1 and 2. The average age of the 37 patients was $44.86 \pm 16.15$ years with a male to female ratio of $(\mathrm{M}: \mathrm{F}-$ $27: 10)$. There was one $(2.7 \%)$ postoperative death on the sixty eighth post-operative day from anastomotic dehiscence with peritonitis, faecal fistula and fluid and electrolyte loss in a man with recurrent descending colon cancer. This same patient had a clinical anastomotic leakage on the eighth post-operative day representing $2.7 \%$. Three patients had superficial wound infection.

Table 1

Results of primary anastomosis in emergency distal colonic resection showing indications, age, operations, complications and duration of hospital stay

\begin{tabular}{|c|c|c|c|c|c|c|c|}
\hline Disease & No. of patients & Mean age in years & Operation & $\begin{array}{l}\text { Wound } \\
\text { infection }\end{array}$ & $\begin{array}{c}\text { Clinical } \\
\text { anastomotic } \\
\text { leak }\end{array}$ & Mortality & $\begin{array}{l}\text { Mean duration } \\
\text { of hospital } \\
\text { stay in days }\end{array}$ \\
\hline Sigmoid volvulus & $22(18: 14)$ & $50.6 \pm 14.41$ & Sigmoid colectomy & 0 & 0 & 0 & $8.87 \pm 1.96$ \\
\hline \multirow[t]{2}{*}{ Colonic cancer } & $9(5: 4)$ & $48.75 \pm 13.00$ & Left hemi-colectomy (4) & 3 & 1 & 1 & $18.13 \pm 20.68$ \\
\hline & & & Sigmoid colectomy (5) & & & & \\
\hline Rectal cancer & $2(1: 1)$ & $29.00 \pm 12.73$ & Anterior resection & 0 & 0 & 0 & $12.00 \pm 2.82$ \\
\hline Trauma & $2(2: 0)$ & $21.50 \pm 9.19$ & Colectomy & 0 & 0 & 0 & $7.5 \pm 0.70$ \\
\hline Faecal fistula & $2(1: 1)$ & $27.25 \pm 7.89$ & Sigmoid colectomy & 1 & 0 & 0 & $12.00 \pm 2.82$ \\
\hline Total & 37 & $44.86 \pm 16.15$ & & $4(10.8 \%)$ & $1(2.7 \%)$ & $1(2.7 \%)$ & $11.76 \pm 11.26$ \\
\hline
\end{tabular}


Table 2

Results of colonic irrigation in emergency distal colonic resection showing duration of operation and irrigation, and volume of fluid for irrigation

\begin{tabular}{llll}
\hline Disease & $\begin{array}{l}\text { Duration of operation } \\
\text { (minutes) }\end{array}$ & $\begin{array}{l}\text { Irrigation time } \\
\text { (minutes) }\end{array}$ & $\begin{array}{l}\text { Volume of fluid } \\
\text { (litres) }\end{array}$ \\
\hline Sigmoid volvulus & $182.33 \pm 42.08$ & $38.87 \pm 7.13$ & $2.87 \pm 0.79$ \\
Colonic cancer & $216.25 \pm 69.68$ & $36.88 \pm 7.53$ & $2.44 \pm 0.78$ \\
Rectal cancer & $195.00 \pm 63.60$ & $37.50 \pm 10.60$ & $2.75 \pm 0.35$ \\
Faecal fistula & $200.00 \pm 56.27$ & $30.00 \pm 0.00$ & $2.50 \pm 0.00$ \\
Trauma & $200.00 \pm 56.57$ & $27.5 \pm 3.54$ & $2.00 \pm 0.00$ \\
\hline & $189.11 \pm 49.23$ & $35.79 \pm 7.25$ & $2.65 \pm 0.73$ \\
\hline
\end{tabular}

Two with faecal fistula whose wound eventually healed with dressing and the third was the earlier mentioned patient who died from recurrent descending colon cancer. The infections occurred on the fourth and seventh postoperative days respectively. The average volume of fluid (saline/Hartmann's) required to achieve a clean colon was $2.65 \pm 0.73$ litres with a range of 1.5 to 5.0 litres. The time taken to achieve a clean colon ranged between 25 to 50 minutes with an average of $33.77 \pm 7.25$ minutes. It was observed that little or no peritoneal contamination by irrigation fluid occurred during intraoperative colonic lavage.

\section{DISCUSSION}

Traditionally, the management of patients with distal colonic emergencies consists of a staged series of operations: initial decompressive colostomy is followed by resection and anastomosis of the colon and finally the colostomy is closed. There is increasing awareness that three stage operations are poorly tolerated and lead to a prolonged hospital stay. The planned sequence of operations is not always completed in the survivors and an unsatisfactory permanent stoma may result. Although the three stage approach to acute left sided colonic lesion may be associated with low mortality rates of five to eleven per cent(9-12), a higher rate of 19 - $48 \%$ have been documented(9,13-15). In a reported case of obstruction distal to the splenic flexure, primary resection carried a $14 \%$ mortality compared with a $35 \%$ mortality for conventional three stage procedure. Primary resection either as Hartmann's procedure or Mickulicz resection practised for both obstruction and perforation thus appears to be relatively safe. However, a further technically demanding laparotomy for reanastomosis may be required and at times not performed. It is common practice to carry out extended right hemicolectomy so as to deal with obstructing lesions of the left side of the colon as far as the proximal sigmoid. However, for lesions at or beyond the apex of the sigmoid, it is not advisable to sacrifice so much of the absorptive surface of the colon as diarrhoea may follow. Thus, colocolic rather than ileocolic anastomosis is preferred for lesions of the descending and sigmoid colon.
Primary resection of the left colon with immediate anastomosis as an emergency has been sporadically reported since 1950(16). Mortality ranges between $6.6 \%$ and 50\% and most are due to anastomotic leakage(17-20). Faecal loading of the obstructed colon is one of the most important factors contributing to anastomotic leakage(1-3). Methods employed for mechanical cleansing of the colon at the time of emergency operation include those of Muir(21), Valero and Jones(22) and Thow(23). Experience by other workers, employing pre-operative antegrade colonic lavage as described by Dudley et al (8) in the management of left sided large bowel emergencies attest that this method provides consistently excellent colonic preparation and also reduces the duration of hospital stay(24-27). Our experience in 37 emergencies is convincing that the technique provides consistently good colonic preparation.

Wound infection rate of $10.3 \%$ in this study appears lower than rates of $25 \%$ to $60 \%$ reported in the Caucacian populations(28-30). This is probably the result of a combination of the relatively few number of patients and selection criteria which ensure that only patient $\mathrm{s}$ presenting with less severe peritonitis, interloop abscesses and faecal contamination were subjected to the procedure. Anastomotic leakage rate of $2.7 \%$ in this study is comparable to a rate of four per cent reported in other series(29,31). Adequate volume replacement, good conduct of anaesthesia and avoidance of technical factors such as adequate bowel mobilisation to avoid anastomosis under tension, anastomosis of healthy bowel ends with sutures carefully placed and of such tension that strangulation of bowel will not occur and general care to prevent trauma to bowel ends are possible significant factors as well. Operative mortality rate of $2.7 \%$ is lower than rates of $4 \%$ to $10 \%$ reported in other series $(30,32)$. Majority of the patients in this series were relatively young and fit and had benign left sided colonic lesions (Sigmoid volvulus) with no intercurrent medical illnesses making them able to withstand the disorder and its surgical treatment. Improved patient health through pre-operative correction of anaemia, fluid and electrolyte deficit, acid base disturbances, were possible additional factors essential to patients survival. The average duration of hospital stay in this series is 11.76 \pm 11.26 days. Similar studies have reported 20 days $(33,34)$. 
The period spent in hospital appears reduced. There seems therefore to have been a saving in hospital bed usage as well as the cost of hospital expenses.

On-table colonic irrigation added 20 - 30 minutes to the operative time. The increase is important. However, with contemporary anaesthetic technique, the additional time did not seem to expose most patients to any markedly increased risk. Furthermore, in our patients most of whom are young with stable circulatory state the extra time is well spent if it avoids the need for a further operation. Gross dilatation of the proximal colon which is a traditional contraindication to primary anastomosis was not a problem in this series as they were found to return to a size comparable with the distal end after decompression by ontable lavage.

We were unable to ascertain anastomotic leakage using radiological method as is usually done in some series. The reason was basically financial and the relatively limited availability of such facilities in our centre. The anastomotic leakage rate may have been much higher if roentgenographic contrast study was routinely done. However, if such a potential radiological leak did occur, it was not significant enough to be picked up clinically. Nongangrenous sigmoid volvulus in our patients who were relatively fit with no absolute contraindication to resection and primary anastomosis constituted the major indication for on-table colonic irrigation in this series.

Resection and primary anastomosis after colonic irrigation was the preferred option in this case because of the unlikelihood of recurrence associated with it. Furthermore, mortality following emergency surgery for acute sigmoid volvulus is low in the developing world despite debilitation resulting from delayed presentation, for example, 5\% in Tanzania, 16\% in Nigeria, $20 \%$ in Sudan(35-37). This may be due to the fact that in the developing world, as in this series, the patients are usually young and healthy(38). Seven of our nine patients had left colonic and sigmoid cancer and presented with features of intestinal obstruction but not suggestive of peritonitis. They had resectable but non-curable cancer. After preoperative homologous blood transfusion in three of them, all were subsequently offered colectomy. Primary anastomosis was particularly avoided in patients who had left colonic resection in the presence of advanced peritonitis and interloop abscesses. However, in patients with less severe peritonitis when operation was undertaken early, the effects of peritonitis were managed by thorough antibiotic lavage, systemic antibiotics, intra-operative colonic lavage and eradication of the source of sepsis by resection. It was thus possible in two of our patients with localised peritonitis to do a primary anastomosis. In the patient with descending colon injury resulting from stab injury, the vessels supplying the segment of the colon were also transected, demanding that colectomy be done.

There is a move towards definitive surgery for left sided large bowel emergency conditions. Our results support the suggestion by others that primary resection, intra-operative colonic irrigation and anastomosis is the treatment of choice for selected left sided large bowel emergency conditions. In view of the obvious advantages such as patient comfort and convenience, short hospitalisation, single instead of staged procedure, primary anastomosis of the large bowel should be carried out more frequently provided the surgeon is competent and the patient reasonably fit and colostomy be reserved for few unavoidable cases. This is very important in our environment where patients are poor, hospital bills high and beds are few.

\section{ACKNOWLEDGEMENTS}

To the Consultant Surgeons at the Jos University Teaching Hospital (JUTH) for their assistance, advice and encouragement.

\section{REFERENCES}

1. Irvin T. T. and Goligner J. C. Aetiology of disruption of intestinal anastomosis. Brit. J. Surg. 1973; 60:461-4.

2. Smith S. R. G., Conolly J. C. and Gilmore O. J. A. The effect of faecal loading on colonic anastomotic healing. Brit. J. Surg. 1983; 70:49-50.

3. Ahrendt G. M., Tantry U. S. and Barbul A. Intra-abdominal sepsis impairs colonic reparative collagen synthesis. Amer. J. Surg. 1996; 171:102-7.

4. Hawley P. J., Hunt K. H. and Dunply J. E. Aetiology of colonic anastomotic leaks. Proc Soc. Med. 1970; 63:28-30.

5. Nwafo D C. Selective primary suture of the battle injured colon: an experience of the Nigerian Civil War. Brit. J. Surg. 1980; 67:195-7.

6. Spencer E. E E. Primary anastomosis of the colon without colostomy. Nig. J. Med. 1991 1:52-4.

7. Onuminya J. E., Obekpa P. O., Ihezue C H. and Momoh J T. Colostomies - indications and complications: the Jos experience 1986 -1991. Nig. Med. J. 1992; 24 suppl.;30-32.

8. Dudley H A F, Radcliffe A G. and McGeeham D. Intraoperative irrigation of colon to permit primary anastomosis. Brit. J. Surg. 1980; 67:80-1.

9. Howe H. J., Casali R. E., Westbrook K. C., Thompson B. W. and Read R. G. Acute perforations of the sigmoid colon secondary to diverticulitis. Amer. J. Surg. 1979; 137:184-7.

10. McSherry C. K., Grafe W. C. R. Jn, Perry H. S. and Gleen F. Surgery of the large bowel for emergent conditions staged $\mathrm{V}$ primary resection. Arch. Surg. 1969; 98:749-53.

11. Miller D. W. and Wichern W. A. Perforated sigmoid diverticulitis: Appraisal of primary versus delayed resection. Amer. J. Surg. $1971 ; 121: 536-40$.

12. Classen J. N., Bonardi R., O’Mara C. S., Finney D. C. W. and Sterioff S. Surgical treatment of acute diverticulitis by staged procedures. Ann. Surg. 1976; 184:582-6.

13. Wara P., Sorensenk, Beck V. and Andrup E. The outcome of staged management of complicated diverticular disease of the sigmoid colon. Acta Chir. Scand. 1981; 147:209-14.

14. Fielding I P. Primary resection for obstructed large bowel cancer. In: De Cosse J J, ed. Clinical Surgery International. Vol I. Large Bowel Cancer. Edinburgh: Churchill Livingstone. 1981: 128-43.

15. Goligher J. C. and Smiddy F. G. The treatment of obstruction or perforation with carcinoma of the colon and rectum. Brit. J. Surg. 1957; 45:270-4.

16. Baronolsky I. D. Primary resection and aseptic end-to-end anastomosis for acute or subacute large bowel obstructions. Surgery 1950; 27:664-72.

17. Ryan P. Emergency resection and anastomosis for perforated 
sigmoid diverticulitis. Brit. J. Surg. 1958; 54:611-6.

18. Boyden A. M. and Neilson D. R. Re-appraisal of the surgical treatment of diverticulitis of the sigmoid colon. Amer. J. Surg. 1960; 160:206-216.

19. Valerio D. and Jones P. F. Immediate resection in the treatment of large bowel emergencies. Brit. J. Surg. 1978; 65:712-6.

20. Farkouh E., Hellou G., Allard M. and Atlas H. Primary anastomosis for diverticulitis with perforation and peritonitis. Can. J. Surg. 1982; 25:314-16.

21. Muir E. G. Safety in colonic resection. Proc. roy. Med. 1968; 61: 401-8.

22. Valero D. and Jones P. F. Immediate resection in the treatment of large bowel emergencies. Brit. J. Surg. 1978; 64:712-6.

23. Thow G. Emergency left colon resection with primary anastomosis. Dis. Colon Rectum 1980; 23:17-24.

24. Koruth N. M., Krukowski Z. H., Yongson G. G., Kendry W. S., Logie J. R. C., Jones P. F. and Munro A. Intraoperative colonic irrigation in the management of left sided large bowel emergencies. Brit. J. Surg. 1985; 72:708-11.

25. Radcliffe A.G. and Dudley H.A.F. Intraoperative antegrade irrigation of large intestine. Surg. Gynaec. Obstet. 1983; 156: 721-3.

26. Chen S.C., Wang S. M. and Wei T. C. Intraoperative irrigation of the colon and primary anastomosis: report of three cases. J. Formos. Med. Assoc. 1993; 92:82-4.

27. Danne P D. Intraoperative colonic lavage: safe single-stage, left colorectal resections. Aust. N. Z. J. Surg. 1991; 61:59-65.

28. Hong J. C., Hwang D. M. and Wang V H. Intraoperative antegrade colon irrigation - in the management of obstructing left-sided colon cancer. Kao Hsiung I Hsueh Ko Hsueh Tsa Chih
1989; 5:309-13.

29. Castrati G., Scotti M., Fiorone E. and Arrigoni G. L'intervento di Hartmann nelle lesioni complicate del retto sigma. Minerva Chir. 1989; 44:1485-8.

30. Amsterdam E. and Krispin M. Primary resection with colocolostomy for obstructive carcinoma of the left side of the colon. Amer. J. Surg. 1985; 150:558-60.

31. Ambrosetti P., Borst f., Robert J., Meyer P. and Rohner A. L'excrese-anastomose en un temps dans les occlusions colliques geuche operees en urgence. Chirurgie 1989;115(suppl 2):IVII.

32. Yu B M. Surgical treatment of acute intestinal obstruction caused by large bowel carcinoma. Chung Hua Wai Ho Tsa Chih 1989; 27:285-6.

33. Sjodahl R., Franzen T. and Nystrom P. O. Primary versus staged resection for acute obstructing colorectal carcinoma. Brit. J. Surg. 1992; 79:685-8.

34. Papanicolaou G., Ahn Y. K., Nikas D. J. and Fielding L. P. Effect of large-bowel obstruction on colonic blood flow. An experimental study. Dis. Colon Rectum. 1990; 32:673-9.

35. Keller A. and Aeberhard P. Emergency resection and primary anastomosis for sigmoid volvulus in an African population. Int. J. Colorect. Dis. 1990; 209-12.

36. Udezue N. O. Sigmoid volvulus in Kaduna, Nigeria. Dis. Colon. Rectum. 1990; 33 :647-9.

37. Taha S. E. and Suleiman S. I. Volvulus of the sigmoid colon in the Gezira. Brit J. Surg. 1980; 67:433-5.

38. Baker D. M., Wardrop P. J. C., Burrel H. and Hardcastle J. D. The management of acute sigmoid volvulus in Notthingham. $J$. roy. Coll. Surg. Edinb. 1994; 39:304-6. 